\title{
Related Factors of Domestic Violence: A Population- Based Research on Iranian Women
}

\author{
Sedigheh Amir Aliakbari ${ }^{1}$, Sanaz Safarzadeh ${ }^{2}$, Fatemeh Bayat ${ }^{3}$, Asiyeh Pormehr-Yabandeh ${ }^{2}$, Sareh \\ Dashti $^{4}$, Nasibeh Roozbeh ${ }^{2}$, Mojdeh Banaei ${ }^{*}{ }^{*}$
}

\begin{abstract}
Objectives: The domestic violence rate is increasing. It is influenced by many factors. The present study aimed to determine the domestic violence level among Iranian women in Bandar Abbas in 2015.

Materials and Methods: The present study is an analytical cross-sectional research based on non-random sampling. The study was performed on 400 women who referred to the health centers in Bandar Abbas, from January to the end of September 2015. The study data were collected using demographic, obstetric and domestic violence questionnaires and were analyzed using SPSS version 22.0. Results: The total degree of domestic violence was $54 \%$. The most prevalent physical, psychological and sexual violence were shouting and swearing (41.4\%) followed by request to have intercourse without your consent (30.8\%) and slapping (25.7\%). A significant relationship was observed between domestic violence and husband's age, marital duration, the wife's independent income as well as the family's income, wife's educational degree and wife's job, husband's addiction, marital satisfaction, a record of criminal conviction, and experience of violence in childhood $(P<0.05)$.

Conclusions: The most frequent type of violence against women was psychological violence in Bandar Abbas. Therefore, screening is recommended for women to improve their health condition.

Keywords: Domestic violence, Violence against women, Torturing wife
\end{abstract}

\section{Introduction}

The World Health Organization (WHO) defined domestic violence as "the range of physically, psychologically and sexually coercive acts used against adult and adolescent women by current or former male intimate partners" (1). Domestic violence is an important health problem in the countries, which devastates the configuration of communities and threatens the individual's life, health and happiness $(2,3)$ Therefore, evaluation of the association between the different types of domestic violence and health consequences is required (4). In general, almost $40 \%$ to $50 \%$ of women reported some levels of domestic violence in their lives (5). Domestic violence threatens the psychological and physical health and sometimes leads to suicide (6). According to a statement by the WHO, preventing domestic violence against women has been presented as one of the most important health priorities (1). According to a national plan conducted in 28 provinces in Iran, $66 \%$ of the studied households reported experiencing violence at least once after marriage and the violence was severe and serious in $30 \%$ and $10 \%$ of the cases, respectively. The study also showed that violence caused a temporary or permanent damage to women (7). Among the main causes of domestic violence are low occupation level, low-income level of families and low education level (8) as well as addiction and criminal conviction of the spouse (9). Other causes of violence may include inadequate family support, substandard dowry given to the bride, smoking, women's lack of an independent source of income, marital dissatisfaction and the absence of consanguineous marriage (10). Furthermore, duration of marriage and being away from family (11), unwanted pregnancy (12), pregnancy more than 6 times, having 4 or more female children and being forced to give birth to a son were reported to be related to violence (11). Among other factors contributing to violence against women are sexual dysfunction, history of psychiatric disorders and experience of violence in childhood (5,11). Domestic violence causes a turbulent relationship between husband and wife which may harm the family relationship and impair psychological health and marital satisfaction (13).

Based on the family systems theory, family members can both influence each other and be affected by other members. Therefore, any problem related to a member causes a challenge and a change in the family system (14). Violence and abuse in families occur frequently with significant impact on children of all ages (15). Studies have

Received 7 March 2017, Accepted 19 September 2017, Available online 9 October 2017

${ }^{1}$ Department of Midwifery, Faculty of Nursing and Midwifery, Shahid Beheshti University of Medical Sciences, Tehran, Iran. ${ }^{2}$ Mother and Child Welfare Research Center, Hormozgan University of Medical Science, Bandar Abbas, Iran. ${ }^{3}$ Department of Midwifery, Zanjan University of Medical Sciences, Zanjan, Iran. ${ }^{4}$ Department of Community Health, Faculty of Medicine and Health Sciences, Universiti Putra Malaysia, 43400 UPM, Serdang, Selangor, Malaysia.

*Corresponding Author: Mojdeh Banaei, Tel: 0098. 9214673694, Fax: +982188202521, Email: Mojdeh.Banaei@gmail.com 
shown that stressful factors lead to feelings of helplessness and lack of control in couples which eventually result in marital crisis (16). Imperfect communication skills also provide an essential contribution to the vulnerability of marital relations (17). The present study aimed to evaluate the domestic violence level and related factors on Iranian women in Bandar Abbas. The findings of this study also provide suitable strategies for preventing, screening, and increasing the awareness of health professionals to identify women at risk and prevent its consequences. These findings are suitable to prevent violence against women, especially pregnant women and promote physical and psychological health in pregnancy and empower women by informing them of their rights. Finally, this research purposed to evaluate the degree of domestic violence and its related factors among women in 2015.

\section{Materials and Methods}

This study is an analytical cross-sectional research conducted from January to the end of September in 2015. The participants of this study were all women who referred to health centers of Bandar Abbas. Subjects were selected from 4 health centers that had the most clients. Subjects were selected using systematic random sampling. The sample size was calculated using the below formula which resulted in 400 subjects:

$n \geq\left[\frac{\left(z_{1-\alpha / 2}+z_{1-\beta}\right)}{0.5 \times \ln [(1+r) /(1-r)]}\right]^{2}+3$

The researcher attended the research centers, presented a written introduction and obtained a written informed consent from the eligible subjects without any coercion, threats, or seduction. Subjects were informed about the research procedure, objective and duration of data collection. Subjects were preferably chosen among the married women who had the ability to understand the questions and were from Bandar Abbas. Systematic random and purposive sampling methods were applied in this study. Thus, the researcher went to the selected health centers and completed the questionnaires for the eligible individuals who were willing to take part in the study.

The data collection tools included demographic and reproductive characteristics as well as the Domestic Violence Questionnaire. The Domestic Violence Questionnaire defines violence as any kind of violent act committed by a husband that is measured in three forms of physical, psychological, and sexual abuse. The women who gave at least one positive response to the questions of the Domestic Violence Questionnaire were regarded as abused.

A questionnaire which was prepared by Iranian researchers was used to collect information on violence. The questionnaire was developed according to the social and cultural conditions of Iranian society and its validity and reliability were assessed previously $(18,19)$. The questionnaire included 26 items (the first 10 items on physical violence, 5 items on sexual violence, and 11 items on psychological violence) based on the 5-point Likert scale (never, one time, 2 times, 3-5 times, more than 5 times). Since the questions were adjusted according to the specific conditions and requirements of the target group in the current study, the validity and reliability of the questionnaire were tested again. The content validity of the questionnaire was approved by a panel of experts in the field and the face validity was confirmed in a pilot study on 15 women. The internal reliability of the questionnaire was acceptable (Cronbach $\alpha=0.85$ ).

\section{Statistical Analysis}

Finally, the data were extracted and analyzed using descriptive statistics (mean, SD, frequency, and percentage) and analytical statistics (logistic regression) by the Statistical Package for Social Sciences (SPSS) software version 22.0 (IBM ${ }^{\odot}$ Corp., Armonk, NY USA). A $P$ value less than 0.05 was considered significant.

\section{Results}

All women were interviewed. The response rate was 100\%. The mean age of subjects was $32.74 \pm 8.39$ years and the mean spousal age was $36.25 \pm 9.26$ years. Consanguineous marriage was observed in $27 \%$ of the subjects. Most of the subjects (50.3\%) had academic education, $49.7 \%$ had a diploma or lower levels of education, and $44.3 \%$ of the subjects had husbands with academic education, $55.7 \%$ had a diploma or lower levels of education. The average marital duration was $10.76 \pm 9.8$ years. Housewives comprised $55.10 \%$ of the subjects. Family income of the majority of subjects (58\%) was more than 10 million Rials monthly. Most of the subjects (54.70\%) lived in their own houses and the others lived in organizational houses, rented houses, or with their spouse parents (with their inlaws). The average household size in this study was $3.49 \pm$ 1.41 and the average number of children was $1.54 \pm 1.56$.

The prevalence of violence is reported in Table 1 . The majority of violence experience was related to psychological violence (54.5\%) followed by physical violence $(39.8 \%)$, and sexual violence $(35 \%)$. The most prevalent physical, psychological and sexual violence was shouting and swearing (41.4\%) followed by the request to have intercourse without your consent $(30.8 \%)$ and slapping $(25.7 \%)$.

The results of logistic regression test indicated that there was a significant association between domestic violence and husband's age $(P=0.012$, odds ratio $[\mathrm{OR}]=0.91)$, duration of marriage $(P=0.001, \mathrm{OR}=1.11)$, wife's economic independence $(P=0.032, \mathrm{OR}=0.65)$, family's income $(P=0.005, \mathrm{OR}=0.54)$, wife's educational level $(P=0.028, \mathrm{OR}=1.51)$, wife's occupation $(P=0.02$, $\mathrm{OR}=0.34)$, spousal addiction $(P=0.041, \mathrm{OR}=0.48)$, marital satisfaction $(P=0.0025, \mathrm{OR}=0.97)$, record of criminal conviction $(P=0.05, \mathrm{OR}=0.21)$, and experience 
Table 1. Distribution of Violence Against Women in Bandar Abbas in 2015

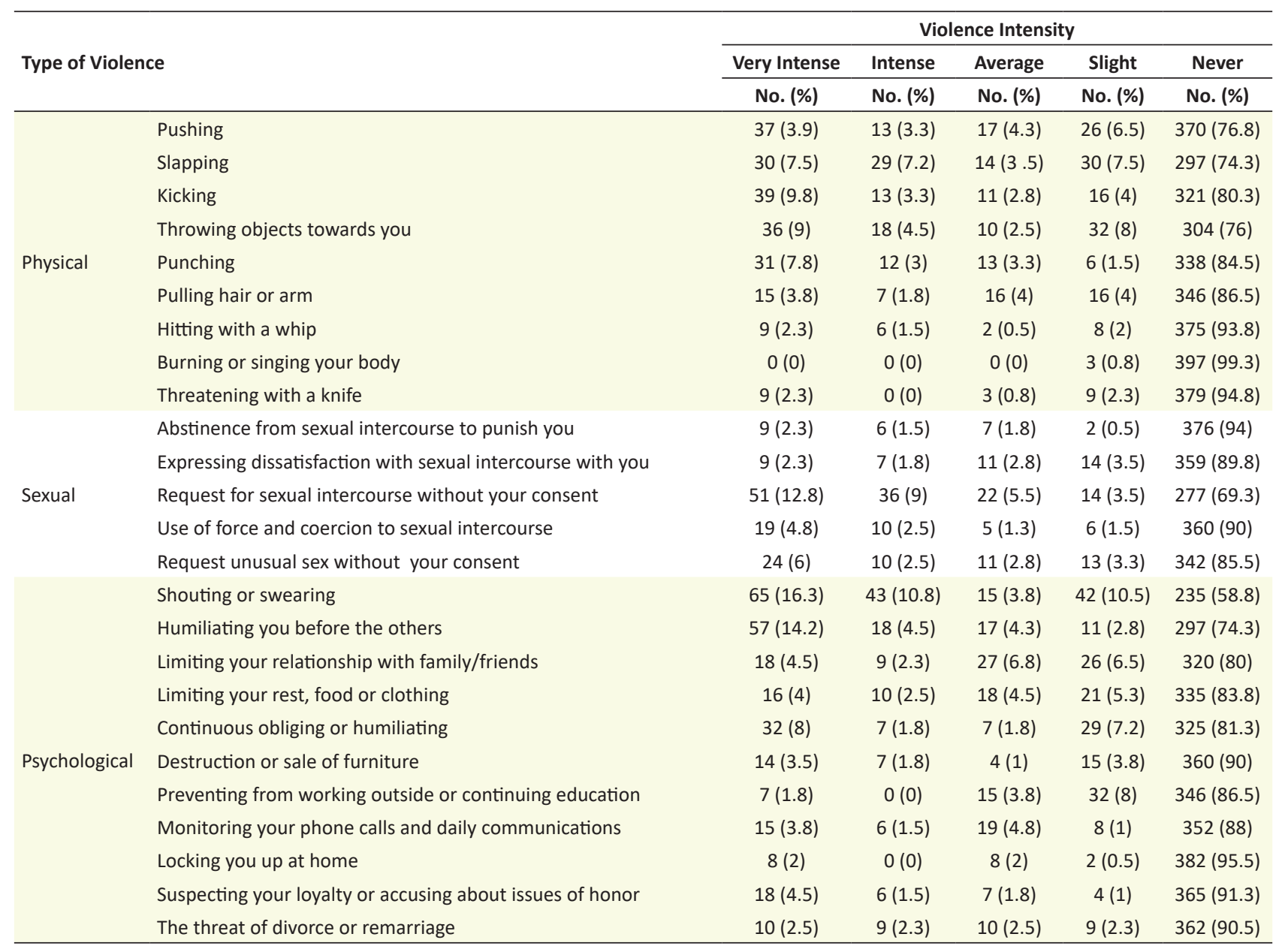

of violence in childhood by wife or husband $(P=0.001$, $\mathrm{OR}=0.44)$ (Table 2).

Based on the obtained results, most of the subjects (62.7\%) chose logically speaking to their husbands and appeasement toward their husbands (35.8\%) in facing with the spousal violence (Table 3).

\section{Discussion}

The prevalence of domestic violence among women is increasing and is affected by many factors. The findings of the present study showed that the majority of violence experience was related to psychological violence (54.5\%) followed by physical violence (39.8\%), and sexual violence (35\%). However, findings of another study in Bandar Abbas indicated that domestic violence among women was $92 \%$, which was much higher than the global statistics $(11,13,20)$. A probable reason for the difference between the findings of this study and the previous studies might be the sampling context. The sampling of this study was done based on the referrals from nearby cities to a training hospital in Bandar Abbas. The incidence of domestic violence against women was reported to be $27 \%$ in Karaj (21), 35.7\% in Tehran (22), 36\% in Babol (23), 83.3\% in Tonekabon (24), $47.3 \%$ in Khouzestan (18), $46 \%$ in
Kerman (19) and 49.4\% in Jahrom (4).

In the present study, the most prevalent applied violence against women in Bandar Abbas was psychological violence (45\%) which is in line with the results of a study by Derakhshanpour (25) on a similar statistical population. Nearly $54 \%$ of women experienced psychological violence. In the studies carried out by Malek Afzali et al in Isfahan (26), Narimani and Aghamohammadian in Ardebil (27), and Salehi and Mehralian in Shahre Kord, the most prevalent type of violence was psychological violence (10). In a study conducted by Hesami et al, the most common violence before pregnancy was the sexual and psychological (emotional) violence (28).

In a study carried out by Arefi on women in Urmia, the most prevalent type of domestic violence against women was physical violence. The most prevalent psychological violence was shouting and swearing, which can result in more serious problems, including family breakdown and different physical violence (29). The findings of the current research were in accordance with some other studies $(18,20,21,25)$. It seems that physical violence decreases in line with the cultural and social changes while psychological violence increases (26). However, it is difficult to separate the different types of violence 
Table 2. The Results of Logistic Regression for Determining the Factors Influencing Domestic Violence

\begin{tabular}{|c|c|c|c|c|}
\hline \multirow{2}{*}{ Variables } & \multirow{2}{*}{ OR } & \multicolumn{2}{|c|}{$95 \% \mathrm{Cl}$ of $\mathrm{OR}$} & \multirow{2}{*}{$\boldsymbol{P}$} \\
\hline & & Lower & Upper & \\
\hline Age & 0.99 & 0.93 & 1.06 & 0.823 \\
\hline The husband's age & 0.91 & 0.85 & 0.98 & $0.012 *$ \\
\hline Marital duration & 1.11 & 1.05 & 1.18 & $0.001 *$ \\
\hline Family relationship with husband & 1.25 & 0.79 & 1.98 & 0.332 \\
\hline Wife's educational level & 0.47 & 0.30 & 0.73 & $0.001 *$ \\
\hline Husband's educational level & 0.84 & 0.62 & 1.14 & 0.287 \\
\hline Wife's job & 0.34 & 0.01 & 0.76 & $0.02 *$ \\
\hline Husband's job & 1.30 & 0.71 & 2.38 & 0.386 \\
\hline Wife's independent income & 0.65 & 0.33 & 0.86 & $0.032 *$ \\
\hline Family income & 0.54 & 0.38 & 0.98 & $0.005^{*}$ \\
\hline Housing status & 1.11 & 0.88 & 1.41 & 0.363 \\
\hline Husband's addiction & 0.48 & 0.32 & 0.89 & $0.041^{*}$ \\
\hline Living with other family members & 0.95 & 1.11 & 0.87 & 0.679 \\
\hline Giving dowry & 0.93 & 0.54 & 1.61 & 0.820 \\
\hline Marital satisfaction & 0.97 & 0.96 & 0.99 & $0.002^{*}$ \\
\hline Unwanted pregnancy & 0.92 & 1.22 & 0.89 & 0.052 \\
\hline Husband's record of criminal conviction & 0.21 & 0.45 & 0.98 & 0.05 \\
\hline Distance from family & 1.09 & 0.63 & 1.87 & 0.744 \\
\hline Experience of violence in childhood of wife or husband & 0.44 & 0.58 & 0.78 & $0.001^{*}$ \\
\hline
\end{tabular}

Abbreviations: OR, odds ratio.

$d f=1$.

* Significant at $P=0.05$.

Table 3. The Frequency Distribution of the Women's Reaction Against Violence

\begin{tabular}{|c|c|c|c|}
\hline \multirow{2}{*}{ Action Against Violence } & Yes & No & Sometimes \\
\hline & No. (\%) & No. (\%) & No. (\%) \\
\hline Silence and appeasement & $143(35.8)$ & $128(32)$ & $129(32.3)$ \\
\hline Counterclaim & $89(22.3)$ & $176(44)$ & $135(33.8)$ \\
\hline Logical speaking to husbands to solve the problem & $251(62.7)$ & $57(14.2)$ & $90(22.5)$ \\
\hline Consulting with her family to solve the problem & $94(23.5)$ & $220(55)$ & $84(21)$ \\
\hline Consulting with her husband's family to solve the problem & $87(21.8)$ & $231(57.8)$ & $82(20.5)$ \\
\hline \multirow{2}{*}{$\begin{array}{l}\text { Consulting with the friends and Acquaintances to solve the problem } \\
\text { Huff and leaving home }\end{array}$} & $82(20.5)$ & $264(66)$ & $54(13.5)$ \\
\hline & $34(8.5)$ & $323(80.8)$ & $43(10.8)$ \\
\hline Complain to the family courts & $25(6.3)$ & $349(87.3)$ & $26(6.5)$ \\
\hline
\end{tabular}

because almost all types happen at the same time; for example, physical and sexual violence set the scene for psychological violence, or vice versa (25).

Houry et al in the United States estimated the prevalence of violence to be $36 \%$. The prevalence rate of various types of the domestic violence was different. The emotional violence was the most prevalent. The physical and sexual violence were $22 \%$ and $9 \%$, respectively. The prevalence of domestic violence in Bosnia and Herzegovina was reported to be $75.9 \%$ and the prevalence rates of emotional, physical and sexual violence were 69.6\%, 63.2\% and $43.5 \%$, respectively (30).

Researchers believe that the cultural and social differences between societies, difference in terms of wife, husband, law and researcher's instances of violence, differences in data collection tools, differences in the profile of subjects, the level of awareness among women about their rights and laws in the various societies, and the presence or absence of organizations supporting women could be among the reasons for differences in the prevalence of violence and its variants.

The findings of the current research indicated that there was a significant association between domestic violence and husband's age, marital duration, the wife's economic independence, family income, wife's education level, wife's occupation, spousal addiction, marital satisfaction, a record of criminal conviction, and experience of violence in childhood. However, there was not any significant relationship between age, family connection with the husband, the husband's educational level, the spousal occupation, housing status, giving dowry, unwanted pregnancy, and being far from family and domestic violence. In general, the findings of this study revealed factors that influence husband violence against women. In fact, violence in women is an innate social problem that arises from a patriarchal family structure.

In a research by Balali Meibodi and Hassani, it was observed that there was relationship between domestic 
violence and husband and wife's educational level $(P<0.05)$, spouse's occupation $(P=0.001)$, being raised in a village up to the age of $20(P=0.023)$, spousal addiction $(P=0.001)$, and living with the other family members $(P=0.001)(19)$. Another study suggests that the prevalence of domestic violence was more common in women whose spouses were alcoholic, had lower literacy levels, were poor or had a record of prison or detention or were drug addicts. There was a negative strong association between the domestic violence and the individual's educational level (10).

In the present study, no association was observed between spouse's levels of education and domestic violence but there was a significant relationship between the wife's educational level and the domestic violence. In a study, the researchers found a significant relationship between the husband's educational level $(P=0.016)$ and the degree of domestic violence in a way that the amount of domestic violence in the illiterate men or men with educational level lower than diploma were significantly more than the other two groups (diploma, associate, bachelor's degree, and higher) (10).

In the current research, it was shown that there is a significant relationship between the monthly income of family (economic status) and the domestic violence. Bonomi et al found that only low income (less than $\$ 25000$ each year) had a significant relationship with the domestic violence (31). However, in another study, no significant relationship was observed between the family's economic status and domestic violence (32). The differences in the results of these studies can be due to the different data collection instruments as in the present study, the level of income was calculated based on Tooman (Rials). In the current study, the association between the domestic violence, alcohol abuse and addiction of the husband was demonstrated, however, this relationship was not significant in a study by Taherkhani, but smoking was related to the husband's violence $(P=0.002)$ (33).

Cooker et al showed that excessive alcohol consumption by an intimate partner was associated with the violence experience (34). The research by Kazemie Navai showed that there was a relationship between violence, smoking and drug using by husbands (35). There was a significant association between marital satisfaction and the domestic violence in this research. The findings of our study were in line with the findings of a study by Lawrence and Bradbury in which $70 \%$ of aggressive couples reported marital dissatisfaction, while only $28 \%$ of non-aggressive couples reported marital dissatisfaction (36). In addition, in the study of Nayak et al, the satisfaction rate was lower in the abused women (20).

The results of this research demonstrated that the most common reaction among women to the violence was logically speaking to the husband $(62.7 \%)$ followed by appeasement (35.8\%), which were in line with the results of a research by Kargar Jahromi et al (4). Madhani et al reported that women's tolerance was the most frequent reaction and referral to counseling centers and legal complaints as the least frequent cases (37). In the present study, complain to the court was also the least frequent case. In fact, domestic violence in the family is a private affair and women rarely resort to the outsiders help and the abused women usually refrain from referring to the judicial centers. Hence, despite the dissatisfaction with life for various reasons, many women are forced to continue living with their abusive husband due to many reasons such as economic dependence on their husbands, fear of loneliness and child loss, lack of social protection and respect for cultural traditions based on the fact that women are responsible for the quality of relationships after marriage (36).

Lack of autonomy among women further decreases their ability to act against violence. While social standards, especially male-controlled opinions and women's dependence to husbands, likely clarify women's resistance to abuse, their recognition of physical abuse as violence shows that they do not essentially believe it is constantly justified (37).

Although we tried to use a valid tool to measure the degree of violence, the study had some limitations. One of the restrictions of the present study was lack of cooperation by subjects due to their embarrassment and fear of disclosing the completed questionnaire. Furthermore, reporting by the subjects, which has the possibility of recall bias, can result in non-disclosure of violence. On the other hand, obtaining information from only one of the partners can influence the validity of the findings. Due to the fact that violence had been reported in the city of Bandar Abbas, like many other cities, it is suggested that providing suitable strategies for preventing, screening, and increasing awareness among health personnel to identify women at risk of domestic violence and preventing its outcomes would help us deal with domestic violence against women, especially in pregnancy. Preventing violence among women can promote their mental and physical health during pregnancy and empower them by introducing their legal rights. Finally, acculturation is taking place for the individuals' rights and respecting these rights takes place in the society, and thus, the social position of women would be improved by increasing their participation in social and individual affairs. Therefore, acculturation and respecting the women rights are among the preventive strategies suggested in the present study.

\section{Conclusions}

The most common type of violence against women was the psychological violence in this research and a significant association was observed between domestic violence and some related factors. Therefore, routine screening is recommended for women, especially women at risk to improve their health condition at each obstetrics 
and gynecology visit, family planning consultation and prenatal, natal and post-natal assessments. Furthermore, it is recommended that medicine and health sciences students and personnel, especially midwives should be trained regarding screening the demotic violence among women and its major effects, especially in reproductive age. Students and personnel of medicine and health sciences field should be educated regarding the identification of physical and psychological symptoms of the victims of violence and to provide counseling, treat and refer victimized women to legal authorities.

\section{Conflict of Interests}

Authors declare that they have no conflict of interests.

\section{Ethical Issues}

The ethical committee of Shahid Beheshti University of Medical Sciences approved this research design (IR. SBMU.PHNM.1395.517) and permission was obtained from Hormozgan University of Medical Sciences.

\section{Financial Support}

This project was funded by Shahid Beheshti University of Medical Sciences, Tehran, Iran.

\section{Acknowledgements}

The present study was carried out with the help of the research department of Shahid Beheshti University of Medical Sciences and authors would also like to appreciate the participants who contributed to this research.

\section{References}

1. World Health Organization. WHO/WHD Violence Against Women: a Priority Health Issue. Geneva: World Health Organization; 1997.

2. John R, Johnson JK, Kukreja S, Found M, Lindow SW. Domestic violence: prevalence and association with gynaecological symptoms. BJOG. 2004;111(10):1128-1132. doi:10.1111/j.1471-0528.2004.00290.x

3. Ali AA, Yassin K, Omer R. Domestic violence against women in Eastern Sudan. BMC Public Health. 2014;14:1136. doi:10.1186/1471-2458-14-1136

4. Kargar Jahromi M, Jamali S, Rahmanian Koshkaki A, Javadpour S. Prevalence and Risk Factors of Domestic Violence Against Women by Their Husbands in Iran. Glob J Health Sci. 2015;8(5):175-183. doi:10.5539/gjhs.v8n5p175

5. Fourozan AS, Dejman M, Baradaran-Eftekhari M, BagheriYazdi A. A study on direct costs of domestic violence against women in legal medicine centers of Tehran (2002). Arch Iran Med. 2007;10(3):295-300. doi:07103/aim.004

6. Banaei M, Amir Ali Akbari S, Ghalandari S, Eslami K. Assess the comparison of marital satisfaction between the abused and non-abused women. Int J Med Res Health Sci. 2016;5(11):617-624.

7. Center for Women's Participation and Social Affairs Country Ministry. National Research Study of Domestic Violence against Women in 28 Centers in the Country. Tehran: Social Department of Country Ministry; 2001. http://ircmj.com/?page = article\&article_id $=34971$.
8. Ali AA, Yassin K, Omer R. Domestic violence against women in Eastern Sudan. BMC Public Health. 2014;14:1136. doi:10.1186/1471-2458-14-1136

9. Saberian M, Atash Nafas E, Behnam B. Prevalence of domestic violence in women referred to the heath care centers in Semnan (2003). Koomesh J. 2005;6(2):115-122.

10. Salehi $S$, Mehralian $H$. The prevalence and types of domestic violence against pregnant women referred to maternity clinics in Shahrekord, 2003. J Shahrekord Univ Med Sci. 2006;8(2):72-77.

11. Naved RT, Persson LA. Factors associated with physical spousal abuse of women during pregnancy in Bangladesh. Int Fam Plan Perspect. 2008;34(2):71-78. doi:10.1363/ ifpp.34.071.08

12. Khanjani Z, Saedi S, Bahadori J. Factors associated with the severity of domestic violence against women referred to forensic Tabriz (Analysis of the impact of disease and demographic characteristics). Woman \& Study of Family. 2009;2(6):67-84.

13. Fawole OI, Abass LW, Fawole AO. Prevalence of violence against pregnant women in Ibadan, Nigeria. Afr J Med Med Sci. 2010;39(4):293-303.

14. Okour AM, Badarneh R. Spousal violence against pregnant women from a Bedouin community in Jordan. J Womens Health (Larchmt). 2011;20(12):1853-1859. doi:10.1089/ jwh.2010.2588

15. Asgari Nekah M. A study of facilator and inhibitory attitudes roles of parents on development of social selfefficacy in their teenage with mental retardation. The 1st National Congress on Family Pathology; Teharn, Iran: 2004:15.

16. Osofsky JD. Commentary: Understanding the impact of domestic violence on children, recognizing strengths, and promoting resilience: reflections on Harold and Sellers (2018). J Child Psychol Psychiatry. 2018;59(4):403-404. doi:10.1111/jcpp.12902

17. Childress S, Gioia D, Campbell JC. Women's strategies for coping with the impacts of domestic violence in Kyrgyzstan: A grounded theory study. Soc Work Health Care. 2018;57(3):164-189. doi:10.1080/00981389.2017.141 2379

18. Nouhjah S, Latifi SM, Haghighi M, et al. Prevalence of domestic violence and its related factors in women referred to health centers in Khuzestan Province. Behbood. 2011;15(4):278-286.

19. Balali Meybodi F, Hassani M. Prevalence of Violence Against Women by their Partners in Kerman. Iranian Journal of Psychiatry and Clinical Psychology. 2009;15(3):300-307.

20. Nayak MB, Byrne CA, Martin MK, Abraham AG. Attitudes Toward Violence Against Women: A Cross-Nation Study. Sex Roles. 2003;49(7):333-342. doi:10.1023/a:1025108103617

21. Emami Motavali M, Oliyan F, Ahrari K, et al. "Frequency of Domestic Violence in Karaj City". The National Congress of Family Health at the University of Medical Sciences; 2001:30.

22. Ahmadi B, Alimohamadian M, Golestan B, Bagheri Yazdi A, Shojaeezadeh D. Effects of domestic violence on the mental health of married women in Tehran. Journal of School of Public Health and Institute of Public Health Research. 2006;4(2):35-44.

23. Baktiary A. Omidbaksh N. Comparison of background and complication of domestic violence in Babol. Behbood J. 2003;7(4):28-35. [Persian]. 
24. Ghahari S, Panaghi L, Atef Vahid MK, Zarei doost E, Mohammadi A. Evaluating the mental health of spouseabused women. J Gorgan Univ Med Sci. 2007;8(4):58-63.

25. Derakhshanpour F, Mahboobi HR, Keshavarzi S. [Prevalence of Domestic Violence against Women]. J Gorgan Univ Med Sci. 2014;16(1):126-131.

26. Malekafzali H, Mehdizadeh M, Zamani AR, Farajzadegan Z. Surveying domestic violence against women in Isfahan in 2003. Med Sci J Islamic Azad Univ Tehran Med Branch. 2004;14(2):63-67.

27. Narimani M, Agha Mohammadian H. A Study of the Extent of Men's Violence against Women and Its Related Variables among Families Inhabited in Ardabil City. The Quarterly Journal Of Fundamentals Of Mental Health. 2005;7(2728):107-113.

28. Hesami K, Dolatian M, Shams J, Alavi-Majd H. Domestic Violence Before and during Pregnancy among Pregnant Women. Iran Journal of Nursing. 2010;23(63):51-59.

29. Arefi M. Domestic violence against women in yromia. Study of Women. 2001;1(2):119-101.

30. Houry D, Kemball R, Rhodes KV, Kaslow NJ. Intimate partner violence and mental health symptoms in African American female ED patients. Am J Emerg Med. 2006;24(4):444-450. doi:10.1016/j.ajem.2005.12.026

31. Bonomi AE, Thompson RS, Anderson M, et al. Intimate partner violence and women's physical, mental, and social functioning. Am J Prev Med. 2006;30(6):458-466. doi:10.1016/j.amepre.2006.01.015

32. Sadeghi Fasaei S. Domestic violence and its strategy. Iranian Journal of Social Issues. 2002;1:1-36. [Persian].

33. Taherkhani S, Mirmohammadali M, Kazemnejad A, Arbabi M. Association experience time and fear of domestic violence with the occurrence of depression in women. Iran J Forensic Med. 2010;16(2):95-106.

34. Coker AL, Davis KE, Arias I, et al. Physical and mental health effects of intimate partner violence for men and women. Am J Prev Med. 2002;23(4):260-268.

35. Kazemie Navai F. A survey on prevalence, causes and outcomes of domestic violence against pregnant women in hospitals of Tehran medical universities (2004) [dissertation].Tehran: Faculty of Nursing \& Midwifery, Tehran University of Medical Sciences; 2005.

36. Lawrence E, Bradbury TN. Physical aggression and marital dysfunction: A longitudinal analysis. J Fam Psychol. 2001;15(1):135-154. doi:10.1037/0893-3200.15.1.135

37. Madhani FI, Karmaliani R, PatelC, etal.Women's Perceptions and Experiences of Domestic Violence: An Observational Study From Hyderabad, Pakistan. J Interpers Violence. 2017;32(1):76-100. doi:10.1177/0886260515585533

(c) 2018 The Author (s); This is an open-access article distributed under the terms of the Creative Commons Attribution License (http://creativecommons.org/licenses/by/4.0), which permits unrestricted use, distribution, and reproduction in any medium, provided the original work is properly cited. 